\title{
Laparoscopic Distal Pancreatectomy Following Prior Upper Abdominal Surgery (Pancreatectomy and Prior Surgery)
}

\author{
Mushegh A. Sahakyan ${ }^{1,2,3}$ (D) Tore Tholfsen $^{4}$ - Dyre Kleive ${ }^{4}$. Sheraz Yaqub ${ }^{4}$ - Airazat M. Kazaryan ${ }^{1,2,5,6}$. \\ Trond Buanes ${ }^{3,7} \cdot$ Bård Ingvald Røsok $^{4} \cdot$ Knut Jørgen Labori ${ }^{4} \cdot$ Bjørn Edwin ${ }^{1,3,4,7}$
}

Received: 2 August 2020 / Accepted: 31 October 2020 / Published online: 10 November 2020

(C) 2020 The Author(s)

\begin{abstract}
Background and Purpose Previous abdominal surgery can be a risk factor for perioperative complications in patients undergoing laparoscopic procedures. Today, distal pancreatectomy is increasingly performed laparoscopically. This study investigates the consequences of prior upper abdominal surgery (PUAS) for laparoscopic distal pancreatectomy (LDP).

Methods Patients who had undergone LDP from April 1997 to January 2020 were included. Based on the history and type of PUAS, these were categorized into three groups: minimally invasive (I), open (II), and no PUAS (III). To reduce possible confounding factors, the groups were matched in 1:2:4 fashion based on age, sex, body mass index (BMI) and American Society of Anesthesiology grade.

Results After matching, 30, 60, and 120 patients were included in the minimally invasive, open and no PUAS groups, respectively. No statistically significant differences were found in terms of intraoperative outcomes. Postoperative morbidity, mortality and length of hospital stay were similar. Open PUAS was associated with higher Comprehensive Complication Index (33.7 vs 20.9 vs $26.2, p=0.03)$ and greater proportion of patients with $\geq 2$ complications $(16.7$ vs 0 vs $6.7 \%, p=0.02)$ compared with minimally invasive and no PUAS. Male sex, overweight (BMI $25-29.9 \mathrm{~kg} / \mathrm{m}^{2}$ ), diagnosis of neuroendocrine neoplasia, and open PUAS were risk factors for severe morbidity in the univariable analysis. Only open PUAS was statistically significant in the multivariable model.

Conclusions PUAS does not impair the feasibility and safety of LDP as its perioperative outcomes are largely comparable to those in patients without PUAS. However, open PUAS increases the burden and severity of postoperative complications.
\end{abstract}

Keywords Laparoscopy $\cdot$ Pancreatectomy $\cdot$ Surgery $\cdot$ Abdomen $\cdot$ Morbidity

Mushegh A. Sahakyan

sahakyan.mushegh@gmail.com

1 The Intervention Center, Oslo University Hospital, Pikshospitalet, 0027 Oslo, Norway

2 Department of Surgery N1, Yerevan State Medical University After M. Heratsi, Yerevan, Armenia

3 Department of Research \& Development, Division of Emergencies and Critical Care, Oslo University Hospital, Oslo, Norway

4 Department of HPB Surgery, Oslo University Hospital, Pikshospitalet, Oslo, Norway

5 Department of Gastrointestinal Surgery, Østfold Hospital Trust, Grålum, Norway

6 Department of Faculty Surgery N2, I.M. Sechenov First Moscow State Medical University, Moscow, Russia

7 Institute of Clinical Medicine, Medical Faculty, University of Oslo, Oslo, Norway

\section{Introduction}

Laparoscopic distal pancreatectomy (LDP) is becoming a standard modality in the treatment of lesions in the pancreatic body and tail. ${ }^{1,2}$ Together with an expansion of selection criteria, disease-, and patient-specific parameters are gaining more attention in the decision-making process. The association between age, obesity, functional status, tumor size, stage and the outcomes of LDP has been addressed in the literature, also by our research group. ${ }^{3-8}$ Another important aspect in the planning and execution of LDP is patient's previous surgical history, particularly, the presence of prior upper abdominal surgery (PUAS).

Intraperitoneal adhesions following PUAS have been reported in up to $90 \%$ of patients. ${ }^{9}$ These may potentially increase the technical difficulty of laparoscopic procedures resulting in visceral injury, bleeding, and conversion. In 
laparoscopic hepato-pancreato-biliary (HPB) surgery, PUAS has been associated with prolonged operative time, conversion, and postoperative morbidity. ${ }^{9-13}$ To the best of our knowledge, no studies examining the influence of PUAS on the outcomes of LDP have been published to date. Given the increasing number of candidates for this procedure, rigorous evaluation of periprocedural risks associated with PUAS is needed.

The aim of this report was to assess the consequences of PUAS for perioperative results of LDP. Thereby, the experience with LDP in a high-volume referral center for pancreatic surgery was analyzed.

\section{Material and Methods}

Patients were operated at Oslo University Hospital, Rikshospitalet, between April 1997 and January 2020. Information on patient demographics, PUAS, comorbidities, clinical characteristics, perioperative outcomes, and complications was obtained from a prospectively maintained database. Patients without information of previous abdominal surgery were excluded. Based on the presence of PUAS and its technique the patients were enrolled in one of the following groups: minimally invasive (I), open (II), and no PUAS (III). These were compared in terms of perioperative outcomes. To reduce possible confounding factors, the minimally invasive, open and no PUAS groups were matched in 1:2:4 fashion based on the following covariates: age, sex, body mass index (BMI), and American Society of Anesthesiology (ASA) grade. Patients undergoing multiorgan resections or concomitant abdominal surgery were excluded for further standardization of the study groups. The study was approved by the hospital review board according to the guidelines provided by the regional ethics committee.

For more than 20 years LDP has been the standard procedure for lesions in the body and tail of the pancreas at our institution. Surgical technique and perioperative management of these patients have been described previously. ${ }^{14,15}$ LDP was performed by either senior consultant or staff surgeon. Open distal pancreatectomy was done in a very small proportion $(<4 \%)$ of selected patients - usually, due to the need for complex vascular reconstruction.

PUAS was defined as a surgical procedure performed in the upper portion of the peritoneal cavity, i.e., involving any organ located higher than the umbilicus. In open PUAS, a distinct laparotomy scar above the umbilicus was present. In minimally invasive PUAS, involvement of the upper portion of the peritoneal cavity was the key determinant regardless of where the surgical ports were placed. Patients with a history of both minimally invasive and open PUAS were added to the open group. PUAS included surgical procedures on the liver, gallbladder, bile ducts, pancreas, stomach, spleen, small intestine, kidney, adrenal glands, upper retroperitoneum, and diaphragm, as well as colectomy involving the upper abdomen in the dissection area. Conversely, colorectal resections excluding this area, lower abdominal surgery, and gynecological procedures were not considered as PUAS.

Based on the extent of PUAS, it was divided into two typesmajor and minor. Procedures involving one abdominal quadrant (e.g., cholecystectomy, splenectomy, nephrectomy, adrenalectomy) were considered as minor. ${ }^{16,17}$ Conversely, those involving $>1$ abdominal quadrant were regarded as major. The latter included HPB surgery, procedures on the stomach, small bowel, and colon. Patients with a history of both minor and major PUAS were added to the major PUAS group.

Obesity classes were defined based on BMI and categorized according to the World Health Organization criteria, i.e., normal weight $\left(\mathrm{BMI}=18.5-24.9 \mathrm{~kg} / \mathrm{m}^{2}\right)$, overweight $\left(B M I=25-29.9 \mathrm{~kg} / \mathrm{m}^{2}\right)$ and obese $\left(B M I \geq 30 \mathrm{~kg} / \mathrm{m}^{2}\right)$. Conversion to open surgery was defined as laparotomy at any time during surgery, not specifically related to the extraction of the specimen. Intraoperative unfavorable events were defined and graded according to the Oslo classification based on Satava approach to surgical error evaluation. ${ }^{8,18,19}$ Postoperative morbidity was defined as suggested by Clavien and Dindo. ${ }^{20}$ Grade IIIa-V complications were considered severe. The Comprehensive Complication Index (CCI) was used for comprehensive and accurate measurement of postoperative complications. ${ }^{21}$ Postoperative pancreatic fistula (POPF) was reported as suggested in the 2016 update from the International Study Group of Pancreatic Surgery (ISGPS) ${ }^{22}$ Postoperative hemorrhage was defined and graded according to the ISGPS. ${ }^{23}$ The 90 days from surgery definition was used for mortality and readmission. ${ }^{24}$

Mean ( \pm standard deviation) and median (range) values are applied for normally and nonnormally distributed continuous data, respectively. Accordingly, the analysis of variance (ANOVA) and the Kruskal-Wallis test were used to compare normally and nonnormally distributed data, respectively. The post hoc test was used to verify statistically significant differences between the means, and the two-sided Mann-Whitney $U$ test was used for the medians. The categorical variables were shown as numbers (percentages), and the chi-square test or Fisher's exact test were used to compare these. The twosided $p$ value $<0.05$ was considered statistically significant.

Univariable and multivariable analyses were run by using binary logistic regression model. Variables significant at the $p$ value $<0.1$ in the univariable analysis were added to the multivariable model, where the two-sided $p$ value $<0.05$ was considered statistically significant.

\section{Results}

Six hundred twenty-five patients underwent LDP for all indications. Patients without information on PUAS $(n=12)$ and 
Fig. 1 Study flow-chart. Abbreviations: LDPlaparoscopic distal pancreatectomy; PUAS - previous upper abdominal surgery

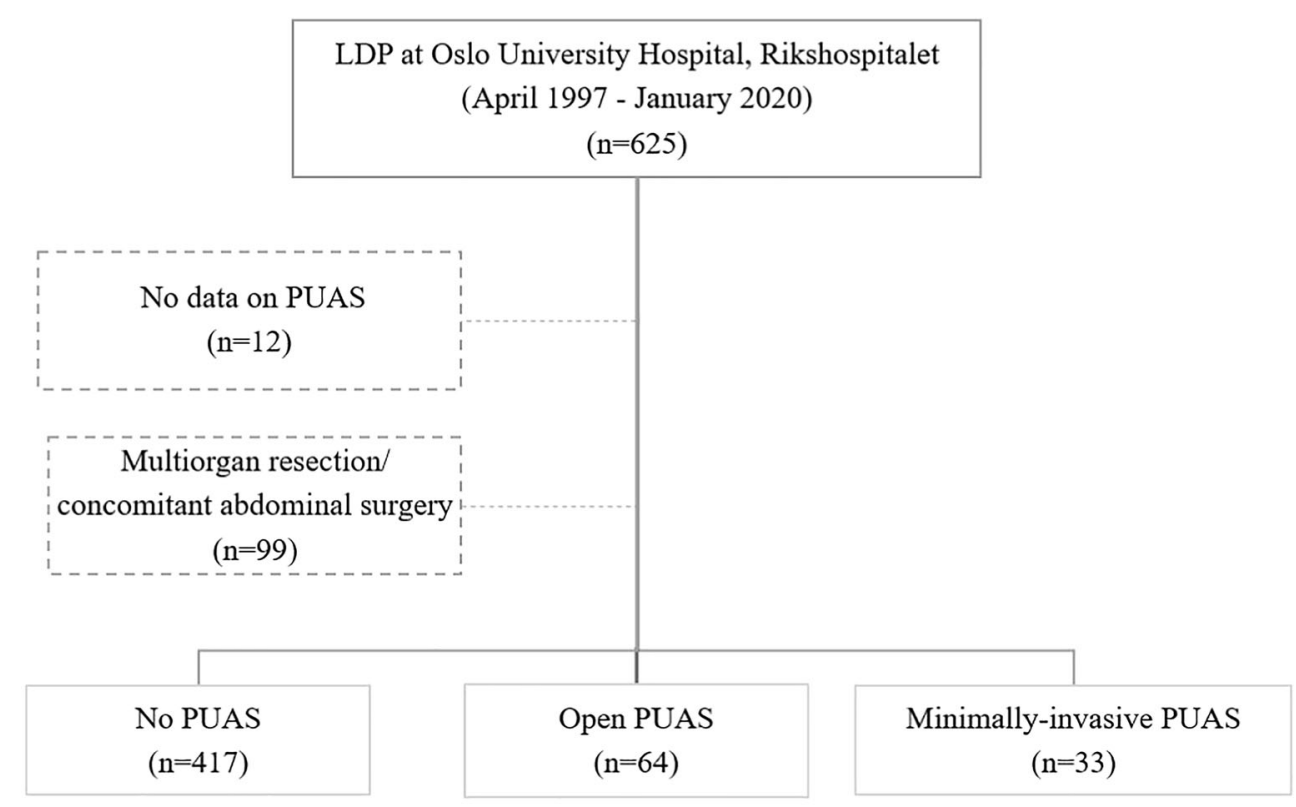

Abbreviations: LDP - laparoscopic distal pancreatectomy; PUAS - previous upper abdominal surgery. those with multiorgan resections/concomitant abdominal surgery $(n=99)$ were excluded (Fig. 1). As a result, 514 patients met the inclusion criteria. Of those, $417(81.4 \%)$ had no surgical history, while $64(12.1 \%)$ and $33(6.4 \%)$ had open and minimally invasive PUAS, respectively. A total number of 78 procedures were performed in open PUAS group and 34 in the minimally invasive group (Table 1). The most common PUAS was cholecystectomy accounting for nearly a quarter of open and more than a half of minimally invasive procedures. There were 34 major open and 8 major minimally invasive PUAS.
After matching, 30, 60, and 120 patients were included in the minimally invasive, open, and no PUAS groups, respectively. No statistically significant differences were found between the groups in terms of baseline characteristics, indications for surgery and spleen-preservation rates (Table 2). Proportions of major PUAS and staff surgeons performing LDP were similar between the groups. One patient without PUAS was converted to open approach due to massive intraoperative bleeding. Intraoperative parameters such as operative time, blood loss, blood transfusion, and intraoperative unfavorable incidents were comparable.
Table 1 Description of previous upper abdominal surgical procedures in open and minimally invasive groups

\begin{tabular}{llll}
\hline Open & $n(\%)$ & Minimally invasive & $n(\%)$ \\
\hline Cholecystectomy & $19(24.4 \%)$ & Cholecystectomy & $20(58.9 \%)$ \\
T-A* nephrectomy/kidney resection & $15(19.2 \%)$ & Hemi/subtotal/total colectomy & $5(14.8 \%)$ \\
Hemi/subtotal/total colectomy & $10(12.8 \%)$ & T-A* nephrectomy/kidney resection & $3(8.8 \%)$ \\
Surgery for small bowel obstruction & $10(12.8 \%)$ & T-A* ventral hernia repair & $3(8.8 \%)$ \\
Total/subtotal gastrectomy & $8(10.3 \%)$ & Total/subtotal gastrectomy & $1(2.9 \%)$ \\
Fundoplication/hiatal hernia repair & $4(5.1 \%)$ & Gastroenterostomy & $1(2.9 \%)$ \\
Liver resection & $4(5.1 \%)$ & Liver resection & $1(2.9 \%)$ \\
Splenectomy & $3(3.8 \%)$ & & \\
Pancreatoduodenectomy & $2(2.6 \%)$ & & \\
Gastroenterostomy & $1(1.3 \%)$ & & $34(100 \%)$ \\
Bile duct resection & $1(1.3 \%)$ & & \\
T-A* adrenalectomy & $1(1.3 \%)$ & & Total \\
Total & $78(100 \%)$ & & \\
\hline
\end{tabular}

*Transabdominal 
The rate of complications was similar, however the median CCI was higher in open PUAS compared with minimally invasive and no PUAS (33.7 vs 20.9 vs 26.2, $p=0.03$ ). A significantly higher proportion of patients with $\geq 2$ complications was observed in the open group compared with no PUAS (16.7 vs $6.7 \%, p=0.04)$, while no such patients were found in the minimally invasive arm. Open PUAS showed a trend towards higher incidence of severe complications ( 30 vs 17.5 vs $13.3 \%, p=0.07$ ). Other postoperative outcomes were similar.

A univariable analysis was performed to identify risk factors for severe complications and to assess the potential role of
PUAS (Table 3). Male sex, overweight, diagnosis of pancreatic neuroendocrine neoplasia, and open PUAS were associated with severe morbidity. In the multivariable analysis, only open PUAS correlated with severe morbidity increasing its likelihood more than three times compared with no PUASOR 3.42 (1.34-8.72), $p=0.01$.

Severe complications were observed in 18 patients with open PUAS. Preoperative data, character of complications, and their management are presented in Table 4. The most common indication for LDP among these patients was neuroendocrine neoplasia (7/18 cases). The majority of patients had a history of either major PUAS or nephrectomy (13/18 cases).
Table 2 Perioperative results of laparoscopic distal pancreatectomy in patients with and without previous upper abdominal surgery (matched cohort)

\begin{tabular}{|c|c|c|c|c|}
\hline \multirow[t]{2}{*}{ Parameters } & \multicolumn{3}{|c|}{ Previous upper abdominal surgery } & \multirow[t]{2}{*}{$p$ value } \\
\hline & $\begin{array}{l}\text { No } \\
(n=120)\end{array}$ & $\begin{array}{l}\text { Open } \\
(n=60)\end{array}$ & $\begin{array}{l}\mathrm{M}-\mathrm{I} \\
(n=30)\end{array}$ & \\
\hline Age, years, mean (SD) & $64(12)$ & $67(11)$ & $64(11)$ & 0.21 \\
\hline Body mass index, $\mathrm{kg} / \mathrm{m}^{2}$, mean (SD) & $26.5(4.4)$ & $25.4(3.6)$ & $26.8(4.5)$ & 0.17 \\
\hline Female sex, $n(\%)$ & $64(53.3 \%)$ & $32(53.3 \%)$ & $16(53.3 \%)$ & 1.0 \\
\hline Comorbidities, $n(\%)$ & $90(75 \%)$ & $48(80 \%)$ & $21(70 \%)$ & 0.56 \\
\hline Number of comorbidities, mean (SD) & $1.5(1.3)$ & $1.4(1.1)$ & $1.5(1.4)$ & 0.82 \\
\hline Major PUAS, $n(\%)$ & - & $26(43.3 \%)$ & $8(26.7 \%)$ & 0.12 \\
\hline ASA, median (range) & $2(2-3)$ & $2(2-3)$ & $2(2-3)$ & 0.55 \\
\hline Diagnosis, $n(\%)$ & & & & 0.2 \\
\hline Ductal adenocarcinoma & $20(16.7 \%)$ & $10(16.7 \%)$ & $3(10 \%)$ & \\
\hline Neuroendocrine neoplasm & $37(30.8 \%)$ & $12(20 \%)$ & $4(13.3 \%)$ & \\
\hline Chronic pancreatitis & $6(5 \%)$ & $2(3.3 \%)$ & $3(10 \%)$ & \\
\hline Other & $57(47.5 \%)$ & $36(60 \%)$ & $20(66.7 \%)$ & \\
\hline Staff surgeon, $n(\%)$ & $20(16.7 \%)$ & $7(11.7 \%)$ & $5(16.7 \%)$ & 0.66 \\
\hline Spleen-preserving procedure, $n(\%)$ & $22(18.3 \%)$ & $7(11.7 \%)$ & $3(10 \%)$ & 0.45 \\
\hline Operative time, min, median (range) & $158(45-428)$ & $155(29-319)$ & $142(73-225)$ & 0.22 \\
\hline Estimated blood loss, $\mathrm{ml}$, median (range) & $50(0-2800)$ & $50(0-1900)$ & $100(0-800)$ & 0.15 \\
\hline Conversion, $n(\%)$ & $1(0.8 \%)$ & $0(0 \%)$ & $0(0 \%)$ & 1.0 \\
\hline Intraoperative unfavorable events, $n(\%)$ & $7(5.8 \%)$ & $5(8.3 \%)$ & $2(6.7 \%)$ & 0.8 \\
\hline Grade II-III unfavorable events, $n(\%)$ & $2(1.7 \%)$ & $1(1.7 \%)$ & $0(0 \%)$ & 1.0 \\
\hline Red blood cell transfusion, $n(\%)$ & $7(5.8 \%)$ & $7(11.7 \%)$ & $0(0 \%)$ & 0.11 \\
\hline Postoperative complications, $n(\%)$ & $42(35 \%)$ & $24(40 \%)$ & $9(30 \%)$ & 0.63 \\
\hline CCI, median (range) ${ }^{*}+$ & $26.2(8.7-54.2)$ & $33.7(8.7-100)$ & $20.9(8.7-26.2)$ & 0.03 \\
\hline Cases with $\geq 2$ complications, $n(\%){ }^{*}+$ & $8(6.7 \%)$ & $10(16.7 \%)$ & $0(0 \%)$ & 0.02 \\
\hline Severe complications, $n(\%)$ & $21(17.5 \%)$ & $18(30 \%)$ & $4(13.3 \%)$ & 0.07 \\
\hline Postoperative pancreatic fistula, $n(\%)$ & $20(16.7 \%)$ & $13(21.7 \%)$ & $5(16.7 \%)$ & 0.7 \\
\hline Hemorrhage (grade $\mathrm{B} / \mathrm{C}), n(\%)$ & $12(10 \%)$ & $5(8.3 \%)$ & $0(0 \%)$ & 0.19 \\
\hline Reoperation, $n(\%)$ & $5(4.2 \%)$ & $6(10 \%)$ & $0(0 \%)$ & 0.13 \\
\hline Mortality, $n(\%)$ & $0(0 \%)$ & $1(1.7 \%)$ & $0(0 \%)$ & 0.43 \\
\hline Readmission, $n(\%)$ & $13(10.8 \%)$ & $8(13.3 \%)$ & $1(3.3 \%)$ & 0.35 \\
\hline Hospital stay, days, median (range) & $6(2-35)$ & $5(2-81)$ & $5(2-34)$ & 0.39 \\
\hline
\end{tabular}

$M-I$ minimally invasive; PUAS previous upper abdominal surgery; ASA American Society of Anesthesiologists; $C C I$ comprehensive complication index. *significant difference between no and open PUAS. ${ }^{+}$significant difference between open and minimally invasive PUAS 
Table 3 Univariable and multivariable analyses of risk factors for severe morbidity following laparoscopic distal pancreatectomy

\begin{tabular}{|c|c|c|c|}
\hline \multirow[t]{2}{*}{ Variable } & \multicolumn{2}{|l|}{ Univariate analysis } & Multivariate analysis \\
\hline & OR $(95 \% \mathrm{CI})$ & $p$ value & OR $(95 \% \mathrm{CI})$ \\
\hline Age & $0.99(0.96-1.02)$ & 0.6 & \\
\hline Male sex & $2.02(1.02-4.0)$ & 0.04 & $2.14(0.84-5.49) 1$ \\
\hline \multicolumn{4}{|l|}{ Obesity class (vs normal weight) } \\
\hline Overweight & $0.5(0.23-1.12)$ & 0.09 & $0.73(0.28-1.8651$ \\
\hline Obese & $1.17(0.5-2.73)$ & 0.72 & \\
\hline Cardiovascular disease & $1.4(0.64-3.06)$ & 0.4 & \\
\hline Hypertension & $0.73(0.36-1.51)$ & 0.4 & \\
\hline COPD & $1.37(0.59-3.19)$ & 0.46 & \\
\hline Diabetes mellitus & $1.29(0.54-3.12)$ & 0.56 & \\
\hline Number of comorbidities & $1.19(0.93-1.53)$ & 0.18 & \\
\hline ASA grades III-IV & $1.76(0.89-3.46)$ & 0.1 & \\
\hline \multicolumn{4}{|l|}{ Diagnosis (vs other) } \\
\hline Neuroendocrine neoplasm & $1.99(0.93-4.26)$ & 0.08 & $2.24(0.85-5.92) 1$ \\
\hline Ductal adenocarcinoma & $1.27(0.49-3.3)$ & 0.62 & \\
\hline \multicolumn{4}{|l|}{ Previous open UAS (vs none) } \\
\hline Open & $2.02(0.98-4.17)$ & 0.05 & $3.42(1.34-8.720) 1$ \\
\hline Minimally invasive & $0.73(0.23-2.29)$ & 0.59 & \\
\hline Multiple (vs single PUAS) & $2.09(0.71-6.17)$ & 0.18 & \\
\hline Previous major UAS & $0.92(0.34-2.5)$ & 0.88 & \\
\hline \multicolumn{4}{|l|}{ Time period (vs 1997-2008) } \\
\hline 2009-2020 & $2.02(0.74-5.5)$ & 0.17 & \\
\hline Spleen-preserving procedure & $0.51(0.17-1.54)$ & 0.23 & \\
\hline Staff surgeon & $1.36(0.56-3.29)$ & 0.49 & \\
\hline Intraoperative unfavorable incident & $1.61(0.48-5.41)$ & 0.44 & \\
\hline Estimated blood loss & $1.001(1.0-1.002)$ & 0.14 & \\
\hline Red blood cell transfusion & $1.61(0.48-5.41)$ & 0.44 & \\
\hline Operative time & $1.003(0.99-1.01)$ & 0.2 & \\
\hline
\end{tabular}

ASA American Society of Anesthesiologists; COPD chronic obstructive pulmonary disease; UAS upper abdominal surgery

Half of these patients experienced $\geq 2$ complications. POPF or intraabdominal abscess requiring percutaneous drainage/ puncture developed in 13 patients. Reoperations were performed for bleeding $(n=3)$, evisceration $(n=2)$, transverse colon necrosis, and perforation $(n=1)$.

\section{Discussion}

This is the first study addressing the role of PUAS in the outcomes of LDP. Our findings show that minimally invasive PUAS neither jeopardizes the intraoperative course nor increases postoperative morbidity, mortality, or length of hospital stay following LDP. At the same time, an increased burden and severity of postoperative complications was revealed for open PUAS. This is in contrast to the previous reports on laparoscopic liver, intestinal, and colorectal resections. ${ }^{10,25-27}$
However, severe complications can hardly be attributed solely to open PUAS. In fact, half of these patients had complications typical for distal pancreatectomy, such as POPF, intraabdominal abscess, and postoperative bleeding. Of note, the rates of POPF and postoperative bleeding were similar between open, minimally invasive and no PUAS. Interestingly, open PUAS was associated with the development of $\geq 2$ complications. The latter were present in half of the patients with open PUAS experiencing severe complications. All of these were elderly patients with a history of major PUAS and/or preexisting medical conditions. Thus, this subgroup seems to be the most affected by the negative impact of open PUAS.

Patients with minimally invasive PUAS had perioperative results similar to those of no PUAS. Since the proportion of major PUAS and other preoperative data were comparable between the minimally invasive and open groups, one may 


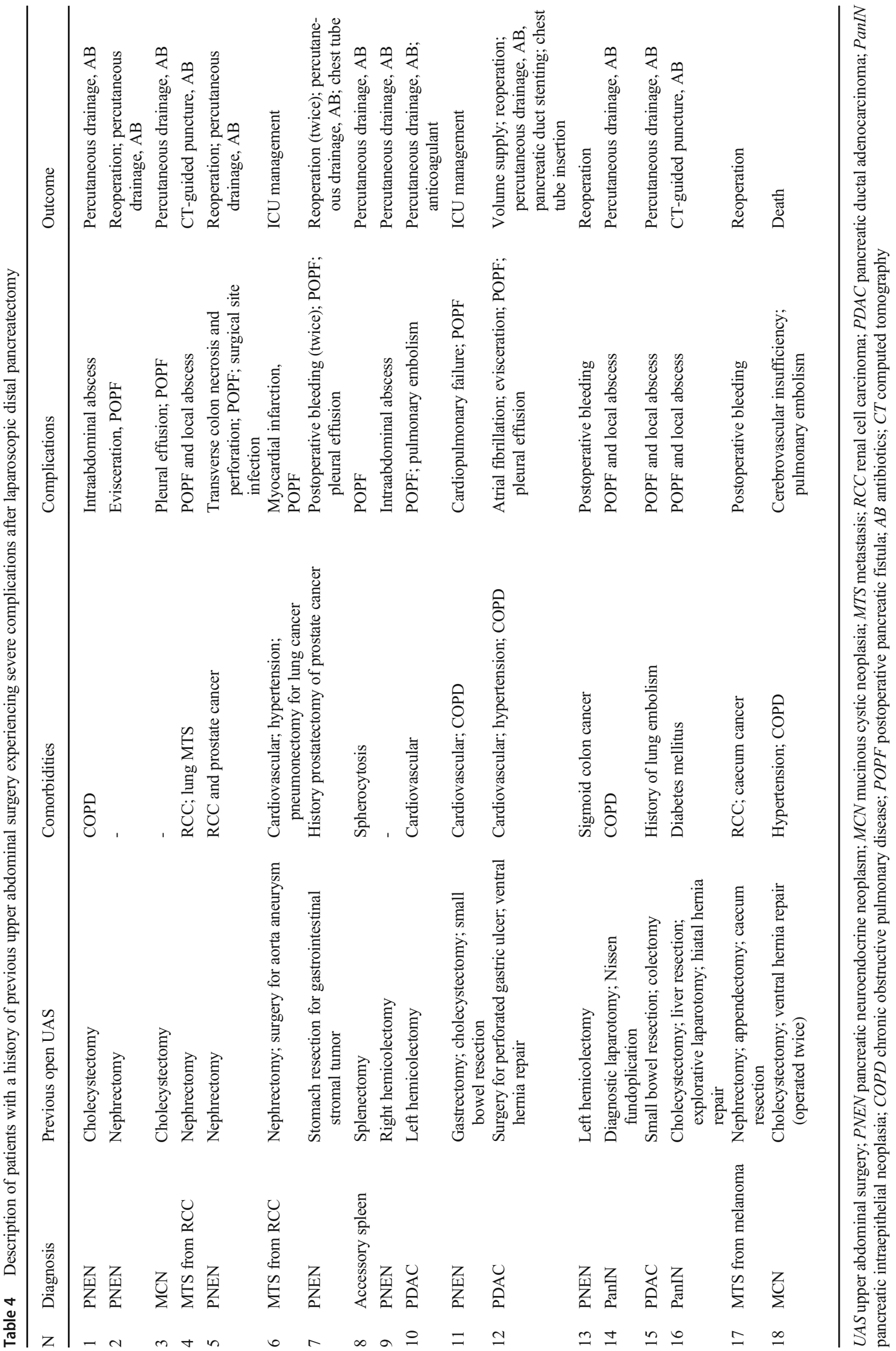


conclude that the former has a potential to mitigate the aforementioned risks of open PUAS. This hypothesis has been successfully tested in laparoscopic liver surgery. ${ }^{28}$ However, given the relatively small number of our patients with minimally invasive PUAS and potential risk for type II error, this assumption seems premature. Registry-based cohort studies are needed to evaluate the impact of minimally invasive PUAS on subsequent LDP.

Another important finding of this audit is that LDP following open or minimally invasive PUAS is associated with intraoperative parameters comparable to those in patients without PUAS. Even previous major surgical procedures such as pancreatoduodenectomy did not increase the intraoperative risks of subsequent LDP. ${ }^{29}$ Remarkably, open PUAS did not increase the likelihood of conversion. Data from a highvolume center in the USA suggest that adhesions are one of the most common causes of conversion during LDP. ${ }^{30}$ Unfortunately, the presence of adhesions was not documented routinely in this study. Furthermore, PUAS itself does not necessarily entail extensive adhesions in the abdomen. However, since nearly half of the open PUAS were major, one should expect to have postoperative adhesions in these patients. At the same time, the vast majority ( $88 \%$ ) of LDP were performed by senior consultants, thus the risk of conversion could have been diminished by the experience of operating surgeons. Several reports have previously underscored the roles of individual surgeon-volume and institution experience in conversion during minimally invasive distal pancreatectomy. ${ }^{30,31}$

The most important drawback of this report is its retrospective design with all inherent biases. Another important limitation is the generalizability of our findings as these are based mostly on a large experience of highly skilled HPB surgeons in an expert center. Finally, the presence of intraabdominal adhesions was not documented routinely, thus there was no possibility to include this parameter in the analysis.

\section{Conclusion}

PUAS itself does not impair the feasibility and safety of LDP as perioperative outcomes are largely comparable to those in patients without PUAS. Open PUAS seems to increase the severity and burden of complications after LDP. This may especially concern the elderly patients with preexisting medical conditions. Further studies should evaluate whether minimally invasive PUAS may mitigate these risks.

Acknowledgements Open Access funding provided by University of Oslo (incl Oslo University Hospital).

Authors' Contributions Study design-Mushegh A. Sahakyan, Knut Jørgen Labori, Trond Buanes, Bjørn Edwin. Data acquisition and
analysis-Mushegh A. Sahakyan, Tore Tholfsen, Dyre Kleive. Data interpretation-Airazat Kazaryan, Sheraz Yaqub, Bård I. Røsok. Manuscript drafting-Mushegh A. Sahakyan, Bjørn Edwin. Critical revision-Tore Tholfsen, Dyre Kleive, Airazat Kazaryan, Sheraz Yaqub, Trond Buanes, Bård I. Røsok, Knut Jørgen Labori. Final approval-Mushegh A. Sahakyan, Tore Tholfsen, Dyre Kleive, Airazat Kazaryan, Sheraz Yaqub, Trond Buanes, Bård I. Røsok, Knut Jørgen Labori, Bjørn Edwin.Agreement to be accountable-Mushegh A. Sahakyan, Tore Tholfsen, Dyre Kleive, Airazat Kazaryan, Sheraz Yaqub, Trond Buanes, Bård I. Røsok, Knut Jørgen Labori, Bjørn Edwin.

\section{Compliance with Ethical Standards}

Conflict of Interest The authors declare that they have no conflict of interest.

Open Access This article is licensed under a Creative Commons Attribution 4.0 International License, which permits use, sharing, adaptation, distribution and reproduction in any medium or format, as long as you give appropriate credit to the original author(s) and the source, provide a link to the Creative Commons licence, and indicate if changes were made. The images or other third party material in this article are included in the article's Creative Commons licence, unless indicated otherwise in a credit line to the material. If material is not included in the article's Creative Commons licence and your intended use is not permitted by statutory regulation or exceeds the permitted use, you will need to obtain permission directly from the copyright holder. To view a copy of this licence, visit http://creativecommons.org/licenses/by/4.0/.

\section{References}

1. Edwin B, Sahakyan MA, Abu Hilal M, Besselink MG, Braga M, Fabre JM, Fernández-Cruz L, Gayet B, Kim SC, Khatkov IE; EAES Consensus Conference Study Group. Laparoscopic surgery for pancreatic neoplasms: the European association for endoscopic surgery clinical consensus conference. Surg Endosc 2017; 31(5): 2023-2041.

2. Asbun HJ, Moekotte AL, Vissers FL, Kunzler F, Cipriani F, Alseidi A, D'Angelica MI, Balduzzi A, Bassi C, Björnsson B, Boggi U, Callery MP, Del Chiaro M, Coimbra FJ, Conrad C, Cook A, Coppola A, Dervenis C, Dokmak S, Edil BH, Edwin B, Giulianotti PC, Han HS, Hansen PD, van der Heijde N, van Hilst J, Hester CA, Hogg ME, Jarufe N, Jeyarajah DR, Keck T, Kim SC, Khatkov IE, Kokudo N, Kooby DA, Korrel M, de Leon FJ, Lluis N, Lof S, Machado MA, Demartines N, Martinie JB, Merchant NB, Molenaar IQ, Moravek C, Mou YP, Nakamura M, Nealon WH, Palanivelu C, Pessaux P, Pitt HA, Polanco PM, Primrose JN, Rawashdeh A, Sanford DE, Senthilnathan P, Shrikhande SV, Stauffer JA, Takaori K, Talamonti MS, Tang CN, Vollmer CM, Wakabayashi G, Walsh RM, Wang SE, Zinner MJ, Wolfgang CL, Zureikat AH, Zwart MJ, Conlon KC, Kendrick ML, Zeh HJ, Hilal MA, Besselink MG; International Study Group on Minimally Invasive Pancreas Surgery (I-MIPS). The Miami International Evidence-Based Guidelines on minimally invasive pancreas resection. Ann Surg 2020; 271(1):1-14.

3. Sahakyan MA, Rosok BI, Kazaryan AM, Barkhatov L, Lai X, Kleive D, Ignjatovic D, Labori KJ, Edwin B. Impact of obesity on surgical outcomes of laparoscopic distal pancreatectomy: a Norwegian single-center study. Surgery 2016; 160(5):1271-1278.

4. Sahakyan MA, Edwin B, Kazaryan AM, Barkhatov L, Buanes T, Ignjatovic D, Labori KJ, Røsok BI. Perioperative outcomes and 
survival in elderly patients undergoing laparoscopic distal pancreatectomy. J Hepatobiliary Pancreat Sci 2017; 24(1):42-48.

5. Chen K, Pan Y, Mou YP, Yan JF, Zhang RC, Zhang MZ, Chen QL, Wang XF. Surgical outcomes of laparoscopic distal pancreatectomy in elderly and octogenarian patients: a single-center, comparative study. Surg Endosc 2019; 33(7):2142-51.

6. Souche R, Fuks D, Perinel J, Herrero A, Guillon F, Pirlet I, Perniceni T, Borie F, Cunha AS, Gayet B, Fabre JM. Impact of laparoscopy in patients aged over 70 years requiring distal pancreatectomy: a French multicentric comparative study. Surg Endosc 2018; 32(7):3164-3173

7. Fernandez-Cruz L, Poves I, Pelegrina A, Burdio F, Sanchez-Cabus S, Grande L. Laparoscopic Distal Pancreatectomy for Pancreatic Tumors: Does Size Matter? Dig Surg 2016; 33(4):290-8.

8. Kazaryan AM, Solberg I, Aghayan DL, Sahakyan MA, Reiertsen O, Semikov VI, Shulutko AM, Edwin B. Does tumor size influence the outcome of laparoscopic distal pancreatectomy? HPB (Oxford) 2019; Dec 13:S1365-182X(19)33213-7.

9. Ahn KS, Han HS, Yoon YS, Cho JY, Kim JH. Laparoscopic liver resection in patients with a history of upper abdominal surgery. World J Surg 2011; 35(6):1333-9.

10. Cai LX, Tong YF, Yu H, Liang X, Liang YL, Cai XJ. Is laparoscopic hepatectomy a safe, feasible procedure in patients with a previous upper abdominal surgery? Chin Med J 2016; 129(4): 399-404.

11. Cipriani F, Ratti F, Fiorentini G, Catena M, Paganelli M, Aldrighetti L. Effect of previous abdominal surgery on laparoscopic liver resection: analysis of feasibility and risk factors for conversion. J Laparoendosc Adv Surg Tech A 2018; 28(7):785-91.

12. Peng L, Cao J, Hu X, Xiao W, Zhou Z, Mao S. Safety and feasibility of laparoscopic liver resection for patients with previous upper abdominal surgery: a systematic review and meta-analysis. Int $\mathrm{J}$ Surg 2019; 65:96-106.

13. Zhu J, Sun G, Hong L, Li X, Li Y, Xiao W. Laparoscopic common bile duct exploration in patients with previous upper abdominal surgery. Surg Endosc 2018; 32(12):4893-9.

14. Rosok BI, Marangos IP, Kazaryan AM, Rosseland AR, Buanes T, Mathisen O, Edwin B. Single-centre experience of laparoscopic pancreatic surgery. Br J Surg 2010; 97(6):902-9.

15. Marangos IP, Buanes T, Rosok BI, Kazaryan AM, Rosseland AR, Grzyb K, Villanger O, Mathisen Ø, Gladhaug IP, Edwin B. Laparoscopic resection of exocrine carcinoma in central and distal pancreas results in a high rate of radical resections and long postoperative survival. Surgery 2012; 151(5):717-23.

16. Kim IY, Kim BR, Kim YW. Impact of prior abdominal surgery on rates of conversion to open surgery and short-term outcomes after laparoscopic surgery for colorectal cancer. PloS one 2015; 10(7): e0134058

17. Lee SY, Kim CH, Kim YJ, Kim HR. Laparoscopic surgery for colorectal cancer patients who underwent previous abdominal surgery. Surg Endosc 2016; 30(12):5472-80.

18. Kazaryan AM, Rosok BI, Edwin B. Morbidity assessment in surgery: refinement proposal based on a concept of perioperative adverse events. ISRN Surg 2013; 2013:625093.

19. Satava RM. Identification and reduction of surgical error using simulation. Minim Invasive Ther Allied Technol 2005; 14(4):25761.

20. Dindo D, Demartines N, Clavien P-A. Classification of surgical complications. Ann Surg 2004; 240(2):205-13.
21. Slankamenac K, Graf R, Barkun J, Puhan MA, Clavien PA. The comprehensive complication index: a novel continuous scale to measure surgical morbidity. Ann Surg 2013; 258(1):1-7.

22. Bassi C, Marchegiani G, Dervenis C, Sarr M, Abu Hilal M, Adam M, Allen P, Andersson R, Asbun HJ, Besselink MG, Conlon K, Del Chiaro M, Falconi M, Fernandez-Cruz L, Fernandez-Del Castillo C, Fingerhut A, Friess H, Gouma DJ, Hackert T, Izbicki J, Lillemoe KD, Neoptolemos JP, Olah A, Schulick R, Shrikhande SV, Takada T, Takaori K, Traverso W, Vollmer CR, Wolfgang CL, Yeo CJ, Salvia R, Buchler M; International Study Group on Pancreatic Surgery (ISGPS). The 2016 update of the International Study Group (ISGPS) definition and grading of postoperative pancreatic fistula: 11 years after. Surgery 2016; 161(3):584-591.

23. Wente MN, Veit JA, Bassi C, Dervenis C, Fingerhut A, Gouma DJ, Izbicki JR, Neoptolemos JP, Padbury RT, Sarr MG, Traverso LW, Yeo CJ, Büchler MW. Postpancreatectomy hemorrhage (PPH): an International Study Group of Pancreatic Surgery (ISGPS) definition. Surgery 2007; 142(1):20-5.

24. Mise Y, Day RW, Vauthey JN, Brudvik KW, Schwarz L, Prakash L, Parker NH, Katz MH, Conrad C, Lee JE, Fleming JB, Aloia TA. After pancreatectomy, the "90 Days from Surgery" definition is superior to the "30 Days from Discharge" definition for capture of clinically relevant readmissions. J Gastrointest Surg 2015; 20(1): 77-84.

25. Aytac E, Stocchi L, De Long J, Costedio MM, Gorgun E, Kessler H, Remzi FH. Impact of previous midline laparotomy on the outcomes of laparoscopic intestinal resections: a case-matched study. Surg Endosc 2015; 29(3):537-42.

26. Kamer E, Acar T, Cengiz F, Durak E, Haciyanli M. Laparoscopic colorectal surgery in patients with previous abdominal surgery: a single-center experience and literature review. Surg Laparosc Endosc Percutan Tech 2017; 27(6):434-9.

27. Yamamoto M, Okuda J, Tanaka K, Kondo K, Asai K, Kayano H, Masubuchi S, Uchiyama K. Effect of previous abdominal surgery on outcomes following laparoscopic colorectal surgery. Dis Colon Rectum 2013; 56(3):336-42.

28. Di Fabio F, Barkhatov L, Bonadio I, Dimovska E, Fretland AA, Pearce NW, Troisi RI, Edwin B, Abu Hilal M. The impact of laparoscopic versus open colorectal cancer surgery on subsequent laparoscopic resection of liver metastases: A multicenter study. Surgery 2015; 157(6):1046-54.

29. Sahakyan MA, Yaqub S, Kazaryan AM, Villanger O, Berstad AE, Labori KJ, Edwin B, Røsok BI. Laparoscopic completion pancreatectomy for local recurrence in the pancreatic remnant after pancreaticoduodenectomy: case reports and review of the literature. J Gastrointest Cancer 2016; 47(4):509-13.

30. Hua Y, Javed AA, Burkhart RA, Makary MA, Weiss MJ, Wolfgang CL, He J. Preoperative risk factors for conversion and learning curve of minimally invasive distal pancreatectomy. Surgery 2017; 162(5):1040-1047.

31. Goh BK, Chan CY, Lee SY, Chan WH, Cheow PC, Chow PKH, Ooi LLPJ, Chung AYF. Factors associated with and consequences of open conversion after laparoscopic distal pancreatectomy: initial experience at a single institution. ANZ J Surg 2017; 87(12):E271E275.

Publisher's Note Springer Nature remains neutral with regard to jurisdictional claims in published maps and institutional affiliations. 